\title{
Comprehensive two-dimensional gas chromatography for fingerprint pattern recognition in olive oils produced by two different techniques in Portuguese olive varieties Galega Vulgar, Cobrançosa e Carrasquenha
}

\author{
L. Torres Vaz-Freire ${ }^{\mathrm{a}}$, M.D.R. Gomes da Silva ${ }^{\mathrm{b}, *}$, A.M. Costa Freitas ${ }^{\mathrm{a}, *}$ \\ a ICAM (Instituto de Ciências Agrárias e Mediterrânicas), Departamento de Fitotecnia, Universidade de Évora, Apt 94, 7002-554 Évora, Portugal \\ ${ }^{\mathrm{b}}$ REQUIMTE, Departamento de Química, Faculdade de Ciências e Tecnologia, Universidade Nova de Lisboa, 2829-516 Caparica, Portugal
}

\section{A R T I C L E I N F O}

\section{Article history:}

Received 11 August 2008

Received in revised form 27 October 2008

Accepted 22 November 2008

Available online 3 December 2008

\section{Keywords:}

Comprehensive two-dimensional gas

chromatography

Olive oil

Volatile organic compounds

Solid phase micro extraction

Fingerprinting

Image treatment

\begin{abstract}
A B S T R A C T
For olive oil production a metal hammer-decanter olive processing line was compared to a traditional metal hammer-press line, a discontinuous method which, if properly used, yields high-quality virgin olive oils. Galega, Carrasquenha and Cobrançosa olives (traditional Portuguese varieties) were studied. The analysis of the aroma compounds was performed after headspace-solid phase micro extraction. The analytical results obtained after comprehensive gas chromatography in tandem with time of flight mass spectrometry (GC $\times \mathrm{GC} / \mathrm{ToFMS})$ for these three different olive oil varieties, from a single year harvest and processed with two different extraction technologies, were compared using statistical image treatment, by means of ImageJ software, for fingerprint recognitions and compared with principal component analysis when the area data of each chromatographic spot of the contour plots were considered. The differences used to classify the olive oils studied under different groups after principal component analysis were observed independently of the treatment used (peak areas or the sum of the pixels counts). When the individual peak areas were considered, more then $75.7 \%$ of the total variance is explained by the first two principal components while in the case where the data were subjected to image treatment $84.0 \%$ of the total variance is explained by the first two principal components. In both cases the first and second principal components present eigenvalues higher then 1.0. Fingerprint image monitoring of the aroma compounds of the olive oil allowed a rapid differentiation of the three varieties studied as well as the extraction methods used. The volatile compounds responsible for their characterization were tentatively identified in a bi-dimensional polar/non-polar column set in the GC $\times$ GC/Tof-MS apparatus. This methodology allowed the reduction of the number of compounds needed for matrices characterization, preserving the efficiency of the discrimination, when compared with the traditional methods where the identification of all peaks is needed.
\end{abstract}

(c) 2008 Elsevier B.V. All rights reserved.

\section{Introduction}

Olive oil production is one of the most traditional agricultural industries in the Mediterranean region, and it is still of primary importance for rural economy, local heritage and environment of most Mediterranean countries. The European Union is the leading world producer, producing around $80 \%$ of the world's olive oil and consuming around $70 \%[1,2]$.

Olive trees belong to the Olea europea L. family but among them different cultivars with different characteristics can be found in the world production zones. The most important cultivars used in Portugal are Galega Vulgar, Carrasquenha, Cordovil, Cobrançosa and

\footnotetext{
* Corresponding authors. Tel.: +351 212 948351; fax: +351 212948550. E-mail addresses: mdr@dq.fct.unl.pt (M.D.R.G. da Silva), afreitas@uevora.pt (A.M.C. Freitas).
}

Verdeal [3], which are also the ones responsible for the generation of olive oil under the classification of Protected Denomination Origin (DOP) [3]. The predominant variety is Galega Vulgar, representing $80 \%$ of the olive patrimony in Portugal [4].

Olive oil quality is dependent on region, variety, the degree of maturation of the olives and sanitary conditions, processing/ extraction technology as well as storage duration and conditions $[5,6]$.

Processing is, in fact, a major factor affecting olive oil quality. Pressed oil obtained under the proper processing conditions is usually of great quality. Press extraction was almost the only olive oil extraction process used for centuries. Extraction technology has, however, progressed significantly since the beginning of the seventies, when the centrifugation system appeared. Since than several comparisons were made between the so-called three-phase centrifugation system extraction with the two-phase centrifugation system [7]. When compared to the press system, these processes 
are sometimes considered as producing olive oils of inferior quality [8].

To verify olive oil quality either chemical or sensorial analysis, or both, can be used. Several studies have been carried out comparing aroma compounds, oxidative stability, phenolic compounds, odour and other chemical parameters [9-12]. The novel analytical scale headspace technique of solid phase micro-extraction (SPME) [13] has become a popular, simple, solvent free method for headspace analysis, allowing quantification in both equilibrium and non-equilibrium situations [14,15]. A wide variety of coated fibres offering some degree of sampling selectivity made it a simple, quick, sensitive and versatile method of sample preparation [15-20], even for enantiomeric-GC (e-GC) [21]. Nevertheless, careful experimental procedure and prudent data handling is required.

One dimension-GC (1D-GC) analysis is currently the most widely used technique to analyse volatiles in several matrices. This approach does not mean that full information about sample composition can be obtained. In fact, one-dimensional analysis of volatiles, especially intensive odorants samples, might produce chromatograms with many unresolved peaks which means that too much information will be missing. In former work Giddings and coworker [22] has demonstrated even that this is probably too often the case.

The application of a multimolecular marker approach to fingerprint allows, in an easy and clean way, the identification of certain characteristics [23] without compromising a future quantification if needed [24]. In the last decade, two-dimensional-GC (2D-GC) experienced a broader diffusion mainly due to its selectivity (three dimensions if mass spectrometric data are considered), high sensitivity (allowed by the peak focusing), enhance separation power and speed $[25,26]$. The quantity and variety of information thus provided by 2D-GC systems promoted the increasingly application of chemometrics in order to allow the data interpretation in a useful and potentially easy way [27-32].

Methods which process computer vision-based images have been applied in order to provide solutions to practical measurements [33]. In this context, ImageJ, a Java-based, multithreaded, freely available, open source, platform independent, and public domain image processing and analysis program which was developed at the National Institutes of Health (NIH), USA [34,35] has been investigated in order to process images in the medical, agricultural and geographical domains [36-39], but not yet assayed in 2D-GC data to the best of our knowledge.

In this work the two different extraction technologies for olive oil production, decanter and pressing by hydraulic press, were evaluated by means of volatile compounds analysis made by HS-SPME-GC $\times$ GC/ToF-MS using a longitudinal cryofocusing modulator system (LCMS) [40-46]. The aim was to verify if the differences, used to classify the olive oils studied under different groups, after submitting the individual peak area data, of each contour plot, to labourious principal component analysis, are also identified using Image software and are enough to allow simple image comparisons to be made. The results obtained are discussed. This image comparison, which can be conveniently used on a routine basis, can provide important and rapid information to determine, not only the differences among the olive oils produced, but it can also be a powerful help to improve the detection of frauds as was already suggested elsewhere [47].

\section{Experimental}

\subsection{Sampling}

Experiments were carried out by mechanically processing, under defined conditions, and olives from the Portuguese's cultivars Galega Vulgar, Carrasquenha and Cobrançosa were collected. All olives were harvested at proper and controlled sanitary conditions during the harvest of 2002.

From each cultivar a sample of $120 \mathrm{~kg}$ was used. Fruits were stored in open boxes at ambient temperature $\left(5-15^{\circ} \mathrm{C}\right)$ with reasonable air flow and without direct light incidence. Extraction was made during the next $24 \mathrm{~h}$, before extraction leaves and dirt were removed by washing under cold running water.

\subsection{Extraction technology}

A homogeneous $20 \mathrm{~kg}$ sample was processed every time for each technology under study: a hammer-mill press line (Vieirinox, Portugal) and a hammer-mill integral decanter line (Oliomio, Italy). No water was added to the olive paste in both systems, and a malaxing time of approximately $1 \mathrm{~h}$ was used for both methods as well. Three replicates were made for each extraction/cultivar.

\subsection{HS-SPME-GC $\times$ GC/ToF-MS analysis}

For the SPME procedure an aliquot of $12 \mathrm{~g}$ of olive oil was introduced into a $22 \mathrm{~mL}$ Pyrex vial. The vial was then immediately sealed with a Teflon-lined rubber septum/aluminium cap. The manual SPME holder and the SPME fibres were purchased from Supelco (Bellefonte, PA, USA). The SPME fibre used was a $2 \mathrm{~cm} \mathrm{50/30 \mu \textrm {m }}$ DVB/Carboxen/PDMS which was previously conditioned following the manufacturer's recommendations. Prior to extraction the samples were allowed to homogenize for $5 \mathrm{~min}$. The fibre was exposed to the sample headspace during a suitable sorption period of $30 \mathrm{~min}$

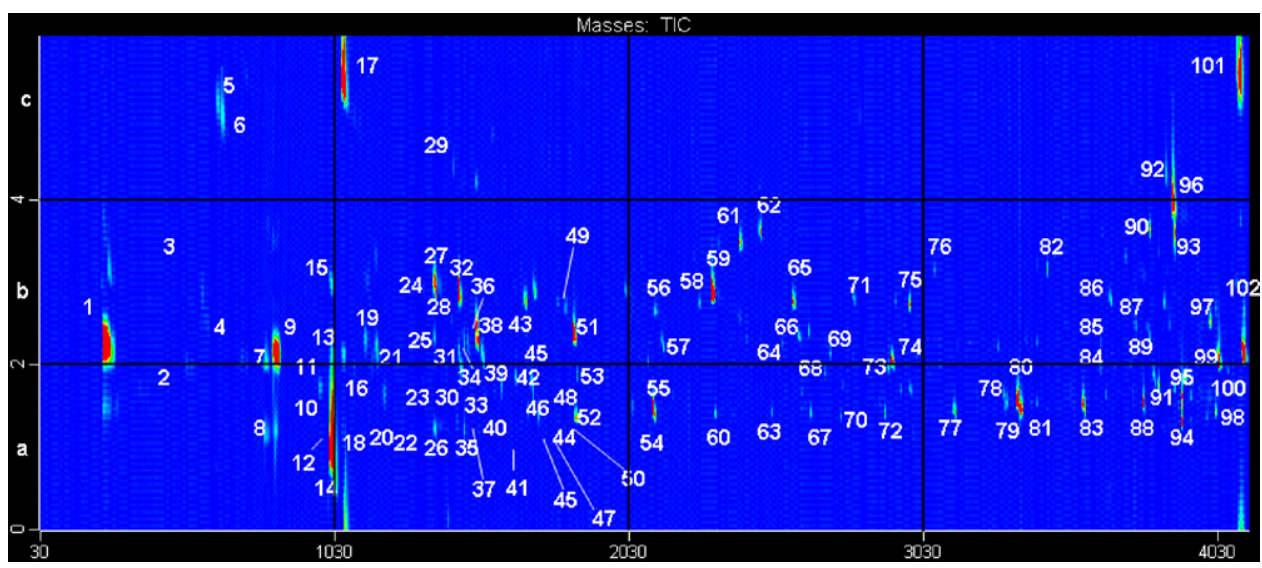

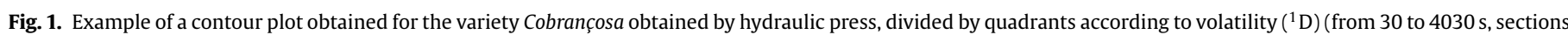
$1-4)$ and polarity $\left({ }^{2} \mathrm{D}\right)$ ( 0 to 6 s sections a-c). 
Table 1

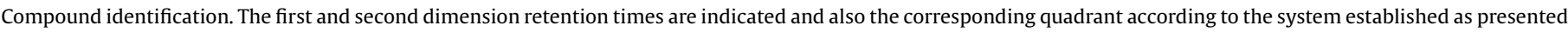
in Fig. 1.

\begin{tabular}{|c|c|c|c|c|}
\hline Compound No. & & Chromatogram Sector & ${ }^{1} t_{\mathrm{R}}$ & ${ }^{2} t_{R}$ \\
\hline 1 & Ethanol & $1 \mathrm{~b}$ & 252 & 2.340 \\
\hline 2 & 3-Methyl-butan-2-one & $1 \mathrm{a}$ & 504 & 2.080 \\
\hline 3 & Pentan-2-one & $1 \mathrm{~b}$ & 504 & 2.990 \\
\hline 4 & 3-Hdroxy-butan-2-one, & $1 \mathrm{~b}$ & 600 & 2.570 \\
\hline 5 & 2-Mthyl-butanol & $1 \mathrm{c}$ & 642 & 5.120 \\
\hline 6 & 3-Methyl-butanol & $1 \mathrm{c}$ & 654 & 5.060 \\
\hline 7 & Hexanal & $1 \mathrm{~b}$ & 828 & 2.170 \\
\hline 8 & 2,4-Dimethyl-heptane & $1 \mathrm{a}$ & 858 & 1.130 \\
\hline 9 & 2,3,5-Trimethyl-hexane & $1 \mathrm{~b}$ & 858 & 2.070 \\
\hline 10 & 2,4-Dimethyl-hept-1-ene & $1 \mathrm{a}$ & 930 & 1.204 \\
\hline 11 & Oct-1-ene & $1 \mathrm{a}$ & 930 & 2.230 \\
\hline 12 & n.i. & $1 \mathrm{a}$ & 1008 & 1.170 \\
\hline 13 & 4-Methyl-octane & $1 \mathrm{a} / \mathrm{b}$ & 1014 & 2.130 \\
\hline 14 & Z-Hex-3-en-1-ol & $1 \mathrm{a}$ & 1020 & 0.870 \\
\hline 15 & Hexen-2-al (isomer) & $1 \mathrm{a}$ & 1020 & 3.040 \\
\hline 16 & E-Hex-3-en-1-ol & $2 b$ & 1062 & 1.250 \\
\hline 17 & Hexanol (wraparound) & $2 c / a$ & 1056 & 5.680 \\
\hline 18 & 2,5-Dimethyl-hepta-1,6-diene & $2 a$ & 1110 & 1.310 \\
\hline 19 & Heptan-2-one & $2 b$ & 1128 & 2.310 \\
\hline 20 & Nonane & $2 \mathrm{a}$ & 1134 & 1.210 \\
\hline 21 & Heptanal & $2 b$ & 1176 & 2.210 \\
\hline 22 & 3-Ethyl-octa-1,5-diene (isomer) & $2 a$ & 1266 & 1.360 \\
\hline 23 & 3-Ethyl-octa-1,5-diene (isomer) & $2 a$ & 1290 & 1.370 \\
\hline 24 & n.i. & $2 \mathrm{~b}$ & 1284 & 1.630 \\
\hline 25 & 1-Ethyl-4-methyl-benzene & $2 b$ & 1368 & 2.150 \\
\hline 26 & Siloxane (column bleed) & $2 \mathrm{a}$ & 1374 & 1.290 \\
\hline 27 & Hept-2-enal (isomer) & $2 b$ & 1374 & 3.030 \\
\hline 28 & Oct-1-en-3-one & $2 b$ & 1428 & 2.620 \\
\hline 29 & Oct-1-en-3-ol & $2 c$ & 1434 & 4.510 \\
\hline 30 & 3-Ethyl-octa-1,5-diene (isomer) & $2 a$ & 1452 & 1.400 \\
\hline 31 & Oct-3-one & $2 b$ & 1452 & 2.210 \\
\hline 32 & 6-Methyl-hept-5-en-2-one & $2 b$ & 1452 & 2.910 \\
\hline 33 & 2-Ethyl-6-methyl-hepta-1,5-diene (isomer) & $2 \mathrm{a}$ & 1464 & 1.470 \\
\hline 34 & Oct-2-one & $2 a$ & 1470 & 2.340 \\
\hline 35 & Decane & $2 \mathrm{a}$ & 1488 & 1.220 \\
\hline 36 & Trimethyl-benzene (isomer) & $2 \mathrm{~b}$ & 1488 & 2.200 \\
\hline 37 & Branched hydrocarbon C11 & & 1506 & 1.220 \\
\hline 38 & Octanal & $2 b$ & 1518 & 2.280 \\
\hline 39 & Limonene & $2 \mathrm{a}$ & 1590 & 1.700 \\
\hline 40 & Branched hydrocarbon C11 & $2 \mathrm{a}$ & 1620 & 1.260 \\
\hline 41 & Branched hydrocarbon C11 & $2 a$ & 1644 & 1.290 \\
\hline 42 & Ocimene (isomer) & $2 \mathrm{a}$ & 1644 & 1.840 \\
\hline 43 & Branched hydrocarbon C11 & $2 b$ & 1644 & 2.220 \\
\hline 44 & Undecane & $2 a$ & 1662 & 1.200 \\
\hline 45 & Branched hydrocarbon C12 & $2 b$ & 1662 & 2.170 \\
\hline 46 & 2,4,6-Trimethyl-non-1-ene & $2 \mathrm{a}$ & 1716 & 1.280 \\
\hline 47 & Branched hydrocarbon C12 & $2 a$ & 1764 & 1.260 \\
\hline 48 & Branched hydrocarbon $\mathrm{C} 12$ & $2 a$ & 1788 & 1.330 \\
\hline 49 & Nonan-2-one & $2 b$ & 1794 & 2.430 \\
\hline 50 & Branched hydrocarbon C12 & $2 a$ & 1836 & 1.280 \\
\hline 51 & Nonanal & $2 \mathrm{~b}$ & 1842 & 2.370 \\
\hline 52 & Siloxane (column bleed) & $2 \mathrm{a}$ & 1848 & 1.370 \\
\hline 53 & 4,8-Dimethyl-nona-1,3,7-triene (isomer) & $2 a$ & 1848 & 1.900 \\
\hline 54 & Dodecane & $3 a$ & 2100 & 1.240 \\
\hline 55 & 3,7-dimethyl-octan-1-ol & $3 a$ & 2112 & 1.490 \\
\hline 56 & Decen-4-al (isomer) & $3 b$ & 2118 & 2.670 \\
\hline 57 & Decanal & $3 b$ & 2148 & 2.220 \\
\hline 58 & Decen-2-al (isomer) & $3 b$ & 2268 & 2.760 \\
\hline 59 & Decen-2-al (isomer) & $3 b$ & 2310 & 2.900 \\
\hline 60 & Tridecane & $3 a$ & 2382 & 1.41420 \\
\hline 61 & Deca-2,4-dienal (isomer) & $3 b$ & 2406 & 3.490 \\
\hline 62 & Deca-2,4-dienal (isomer) & $3 b$ & 2478 & 3.620 \\
\hline 63 & n.i. & $3 a$ & 2514 & 1.450 \\
\hline 64 & n.i. & $3 b$ & 2550 & 2.280 \\
\hline 65 & Undec-2-enal (isomer) & $3 b$ & 2586 & 2.790 \\
\hline 66 & n.i. & $3 b$ & 2604 & 2.380 \\
\hline 67 & Tetradecane & $3 a$ & 2646 & 1.430 \\
\hline 68 & n.i. & $3 a$ & 2694 & 1.930 \\
\hline 69 & n.i. & $3 b$ & 2712 & 2.140 \\
\hline 70 & Siloxane (column bleed) & $3 a$ & 2748 & 1.390 \\
\hline 71 & 6,10-Dimethyl-undeca-5,9-dien-2-one (isomer) & $3 b$ & 2796 & 2.810 \\
\hline 72 & Pentadecane & $3 a$ & 2898 & 1.420 \\
\hline 73 & Aromadendrene & $3 a / b$ & 2910 & 1.980 \\
\hline
\end{tabular}


Table 1 (Continued)

\begin{tabular}{|c|c|c|c|c|}
\hline Compound No. & & Chromatogram Sector & ${ }^{1} t_{\mathrm{R}}$ & ${ }^{2} t_{\mathrm{R}}$ \\
\hline 74 & $\alpha$-Farnesene (isomer) & $3 b$ & 2922 & 2.060 \\
\hline 75 & Farnesol (isomer) & $3 b$ & 2982 & 2.750 \\
\hline 76 & Farnesol (isomer) & $4 \mathrm{~b}$ & 3066 & 3.150 \\
\hline 77 & Hexadecane & $4 a$ & 3138 & 1.430 \\
\hline 78 & Hexadeca-1,9-diene (isomer) & $4 a$ & 3300 & 1.670 \\
\hline 79 & Hexadec-7-ene (isomer) & $4 a$ & 3312 & 1.540 \\
\hline 80 & n.i. & $4 a$ & 3348 & 1.570 \\
\hline 81 & Heptadecane & $4 a$ & 3360 & 1.470 \\
\hline 82 & n.i. & $4 b$ & 3450 & 3.160 \\
\hline 83 & Octadecane & $4 a$ & 3570 & 1.540 \\
\hline 84 & Isopropyl myristate & $4 a$ & 3630 & 1.950 \\
\hline 85 & Dodecanal & $4 \mathrm{~b}$ & 3630 & 2.290 \\
\hline 86 & Farnesol (isomer) & $4 b$ & 3660 & 2.840 \\
\hline 87 & 8-Hydroxylinalool & $4 \mathrm{~b}$ & 3750 & 2.480 \\
\hline 88 & Nonadecane & $4 a$ & 3774 & 1.550 \\
\hline 89 & Hexadec-7-enoic acid methyl ester (isomer) & $4 \mathrm{~b}$ & 3798 & 2.340 \\
\hline 90 & n.i. & $4 \mathrm{~b}$ & 3798 & 3.650 \\
\hline 91 & Hexadecanoic acid methyl ester & $4 a$ & 3828 & 1.760 \\
\hline 92 & Palmitic acid & $4 c$ & 3852 & 4.340 \\
\hline 93 & n.i. & $4 b$ & 3882 & 3.580 \\
\hline 94 & Eicosane & $4 a$ & 3906 & 1.320 \\
\hline 95 & Hexadecanoic acid ethyl ester & $4 a$ & 3906 & 1.640 \\
\hline 96 & n.i. & $4 \mathrm{~b} / \mathrm{c}$ & 3876 & 4.180 \\
\hline 97 & Farnesyl acetate & $4 b$ & 4002 & 2.540 \\
\hline 98 & Heneicosane & $4 a$ & 4020 & 1.440 \\
\hline 99 & Methyl linolelaidate & $4 b$ & 4026 & 2.150 \\
\hline 100 & n.i. & $4 a$ & 4038 & 2.140 \\
\hline 101 & Oleic acid & $4 a / c$ & 4090 & 5.552 \\
\hline 102 & Ethyl linoleate & $4 a$ & 4110 & 2.210 \\
\hline
\end{tabular}

at $40^{\circ} \mathrm{C}$, according to a previous study [48], and introduced into the GC injection port to allow thermal desorption of the analytes at a temperature of $260^{\circ} \mathrm{C}$ for $300 \mathrm{~s}$ period in splitless mode.

The system consisted of a HP 6890 (Agilent Technologies, Burwood, Australia) gas chromatograph and a Pegasus III time-of-flight mass spectrometer (LECO, St. Joseph, MI, USA). To implement the modulation process, a longitudinally modulated cryogenic system (LMCS; Chromatography Concepts, Doncaster, Australia) was used, which was operated at a modulation period of $6 \mathrm{~s}$ with a cryotrap temperature of $-20^{\circ} \mathrm{C}$. The ToF-MS operated at a storage rate of $100 \mathrm{~Hz}$, using a mass range of $45-415 \mu \mathrm{m}$ and a multi-channel plate voltage of $1700 \mathrm{~V}$. Data were processed using LECO Corp ChromaTOF ${ }^{\mathrm{TM}}$ software. The column sets used for GC $\times$ GC experiments comprised a BPX5 (5\% phenyldimethyl polysilphenylene-siloxane phase) primary column of 30 $\mathrm{m} \times 0.25 \mathrm{~mm}$ I.D. $\times 0.25 \mu \mathrm{m}$ film thickness $\left(d_{\mathrm{f}}\right)$, directly-coupled to a BPX20 (polyethyleneglycol phase) column of $1.5 \mathrm{~m} \times 0.1 \mathrm{~mm}$ I.D. $\times 0.1 \mu \mathrm{m} d_{\mathrm{f}}$. Both columns were from SGE International (Ringwood, Australia). The oven temperature was programmed from $35^{\circ} \mathrm{C}$, held for $5 \mathrm{~min}$ and raised to $210^{\circ} \mathrm{C}$ at $3^{\circ} \mathrm{C} \mathrm{min}^{-1}$, then up to $240{ }^{\circ} \mathrm{C}$ at $40^{\circ} \mathrm{C} \mathrm{min}^{-1}$ and held for $10 \mathrm{~min}$ at this temperature. Helium was used at a flow rate of $1.3 \mathrm{~mL} \mathrm{~min}^{-1}$. The interface column for the GC $\times$ GC/ToF-MS system was a 0.50 m deactivated fused silica column with $0.1 \mathrm{~mm}$ I.D. $(0.21 \mathrm{~m}$ inside the transfer line and $0.29 \mathrm{~m}$ inside the oven) also from SGE International. For statistical data treatment, the peak areas considered are the individual areas of all the detected compounds in the contour plot.

\subsection{ImageJ software for image acquisition}

The processed data using LECO Corp ChromaTOF ${ }^{\mathrm{TM}}$ software produced contour plots (images) which were transformed into Jpeg format digital images keeping always homogeneous the surface considered. The GC $\times$ GC experiment, in which two columns were used, one polar and one apolar, in the first and second dimensions $\left({ }^{1} \mathrm{D}\right.$ and $\left.{ }^{2} \mathrm{D}\right)$, respectively, produced a separation based correspondently on volatility and polarity.
Each image was evaluated using the ImageJ software (ImageJ $1.37 \mathrm{v}$, Wayne Rasband, National Institutes of Health, USA).

Each displayed digital image is converted to gray scale ( $8 \mathrm{bit}$ ) images by means of ImageJ software (0-255, where 0 is black, 255 is white, and every point in between these values are a shade of gray). After a threshold has been defined automatically by the software, to promote level equalization, the image pixels which were under the threshold were marked as black, and those above the threshold were marked as white. A binary image from this procedure and a binary image defined by an interpreter were displayed and all pixels were compared. The image was virtually divided in 12 quadrants, and the quantity of pixels which reflect the presence of the different compounds was quantify for each of the 12 quadrants. To the values obtained, a PCA analysis was applied using Statistica 6.0 software (StatSoft Inc.).

\subsection{Statistics}

The GC $\times$ GC/ToF-MS results were submitted to image treatment using ImageJ. After transformation into quantifiable values, the results were compared to the area data (obtained directly after processing the data using LECO Corp ChromaTOF ${ }^{\mathrm{TM}}$ software). ANOVA (Statistica 6.0, StatSoft Inc.), was used to performed this comparison. To test pairwise similarities among means the Tukey test was used with 95\% confidence level. Principal Component Analysis (PCA) was also performed using a sub-routine of the statistical software Statistica 6.0.

\section{Results and discussion}

Two different extraction technologies, decanter (denoted by D) and pressing by hydraulic press $(\mathrm{P})$, were evaluated by means of an analysis of the volatile components in the olive oils. Analysis was performed using HS-SPME-GC $\times$ GC/ToF-MS equipped with a longitudinal cryofocusing modulator system. Three different varieties were studied: Galega, Carrasquenha and Cobrançosa. 
The resulting contour plots of each sample were divided into quadrants with the same size (each $1000 \mathrm{~s}$ in the ${ }^{1} \mathrm{D}$ and $2 \mathrm{~s}$ in the ${ }^{2}$ D). Fig. 1 shows the division referred to by quadrants, where all the sections in the contour plot translate a particular volatility $\left({ }^{1} \mathrm{D}\right)$ and polarity $\left({ }^{2} \mathrm{D}\right)$ of the present compounds, according to the column set used (see Section 2). The compounds present in these sectors are identified in Table 1, organized in quadrants, according to the system established. Through this division, performed for all samples, the total peak area of each quadrant was obtained by the sum of the areas of all the compounds detected in each sector (Supplementary Table S1) and for each quadrant of each contour plot, mapping values were obtained using the ImageJ software (Supplementary Table $\mathrm{S} 2$ ).

\subsection{Data validation-ANOVA, Tukey analysis}

ANOVA after Tukey validation was used to verify if the results, obtained using the ImageJ software, could be considered similar to those obtained from the peak areas, after LECO Corp ChromaTOF ${ }^{\mathrm{TM}}$ software processing, thus allowing a data validation for the image transformation results. When the individual compound areas are obtained, after LECO Corp ChromaTOF ${ }^{\mathrm{TM}}$ software processing, it can be observed that, for the sectors $1 \mathrm{a}, 1 \mathrm{~b}, 2 \mathrm{a}, 2 \mathrm{c}, 3 \mathrm{a}, 3 \mathrm{~b}, 4 \mathrm{a}, 4 \mathrm{~b}$, (sectors assigned according to Fig. 1) the results are significantly different (Fig. 2), while for all the other sectors, significant differences were not verified. Still on Fig. 2, an example of similarity can be observed if sectors 1c, 2b, 3c and 4c are considered. Fig. 3 represents the same study preformed on the data obtained after Image $J$ software treatment. Data from the contour plots $(1000 \mathrm{~s}$ in the ${ }^{1} \mathrm{D}$ and $2 \mathrm{~s}$ in the ${ }^{2} \mathrm{D}$, as indicated above) are divided in quadrants and the values used represents the sum of the areas/pixels from each quadrant. Due to this fact, retention time alignment could be precluded, since the expected highest average standard deviation, considering slightly differences in temperature and pressure programs, of the first and second columns retention times (1.2 s and $0.0035 \mathrm{~s}$, respectively) [31] are correspondently relatively low $-0.12 \%$ of the period of time considered in the ${ }^{1} \mathrm{D}$ $(1000 \mathrm{~s})$ and $0.18 \%$ of the period of time considered in ${ }^{2} \mathrm{D}(2 \mathrm{~s})$. The issue here is, in fact, to consider for each quadrant a surface, defined by the retention times on the ${ }^{1} \mathrm{D}$ and ${ }^{2} \mathrm{D}$, sufficiently high in order to dilute any deviation on both dimensions of a particular compound. In this case each quadrant surface area is more then 200,000 times larger then the highest potential surface area deviations on the ${ }^{1} \mathrm{D}$ and ${ }^{2} \mathrm{D}$. This was already observed before [45-47], when comparisons between GC $\times$ GC-FID, GC $\times$ GC$\mathrm{NPD}, \mathrm{GC} \times \mathrm{GC} / \mathrm{qMS}$ and GC $\times \mathrm{GC} / \mathrm{ToF}-\mathrm{MS}$ data were allowed to be

\section{Areadata after LECO Corp ChromaTOF-TMsoftware processing}

C
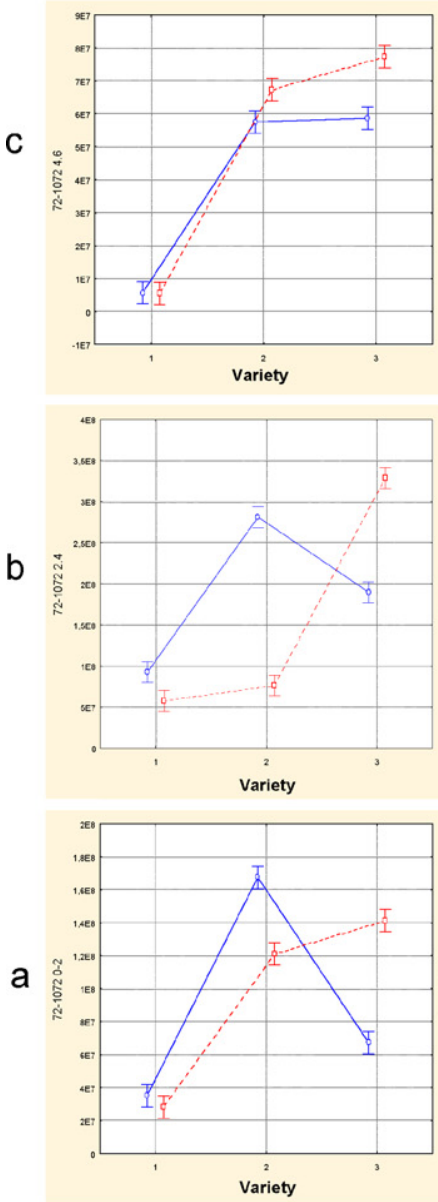

1

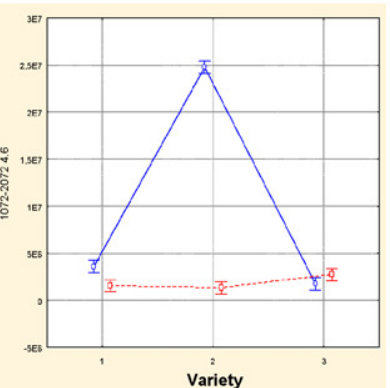

Variety
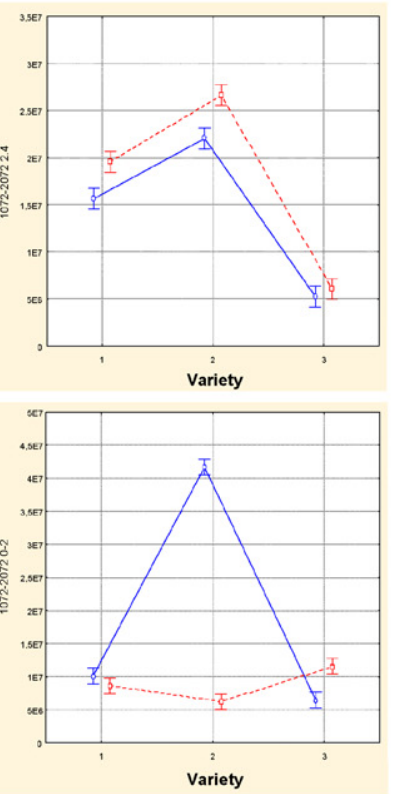

2
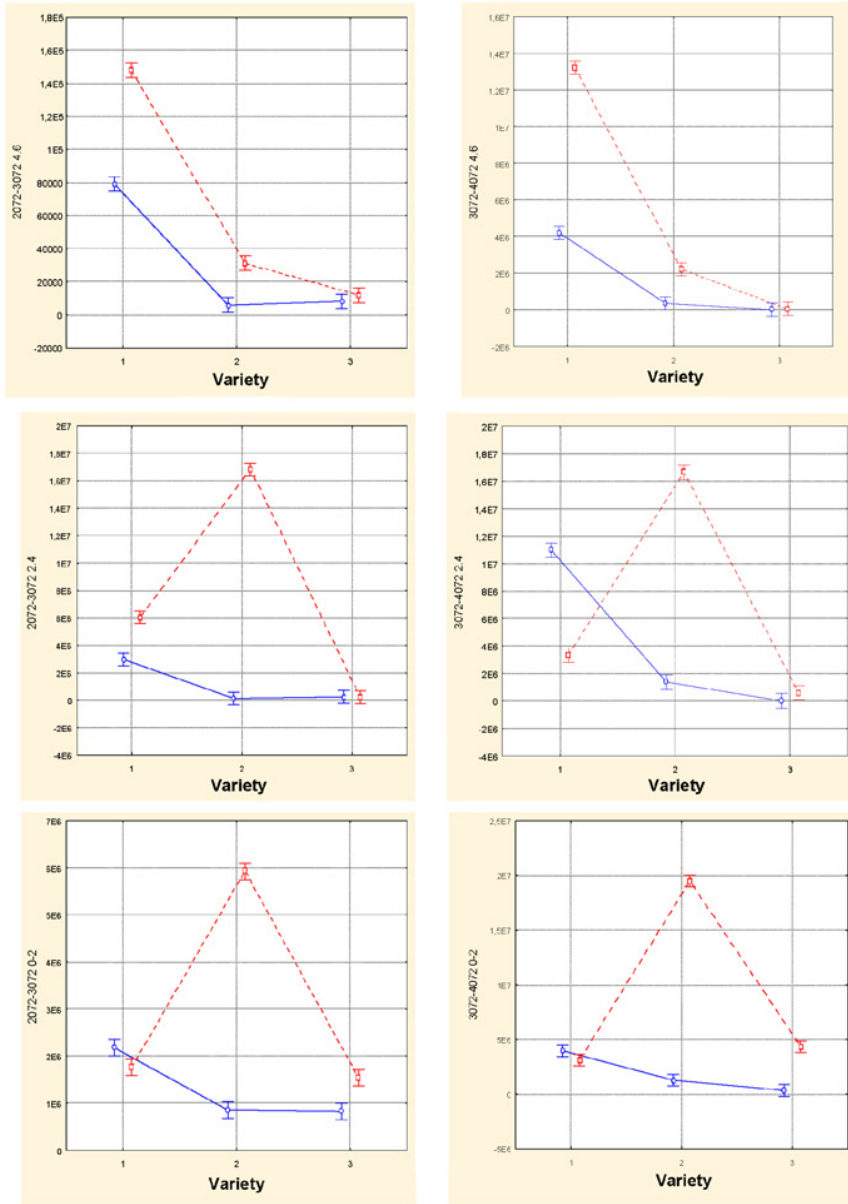

3

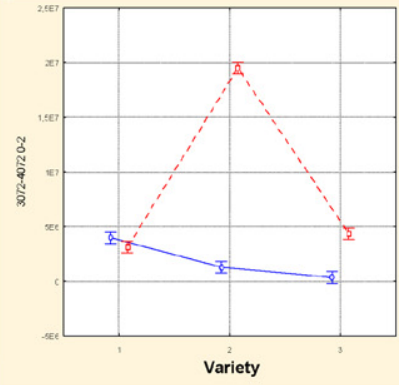

4

---Press

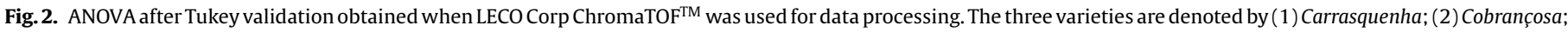

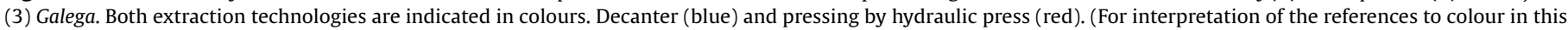
figure legend, the reader is referred to the web version of the article.). 


\section{Sector areasafter ImageJ processing}

C

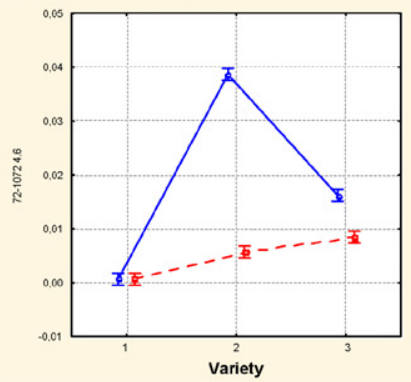

b

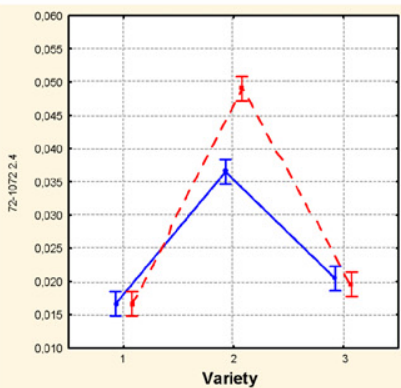

a

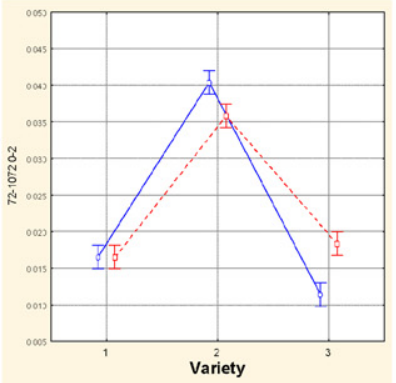

1
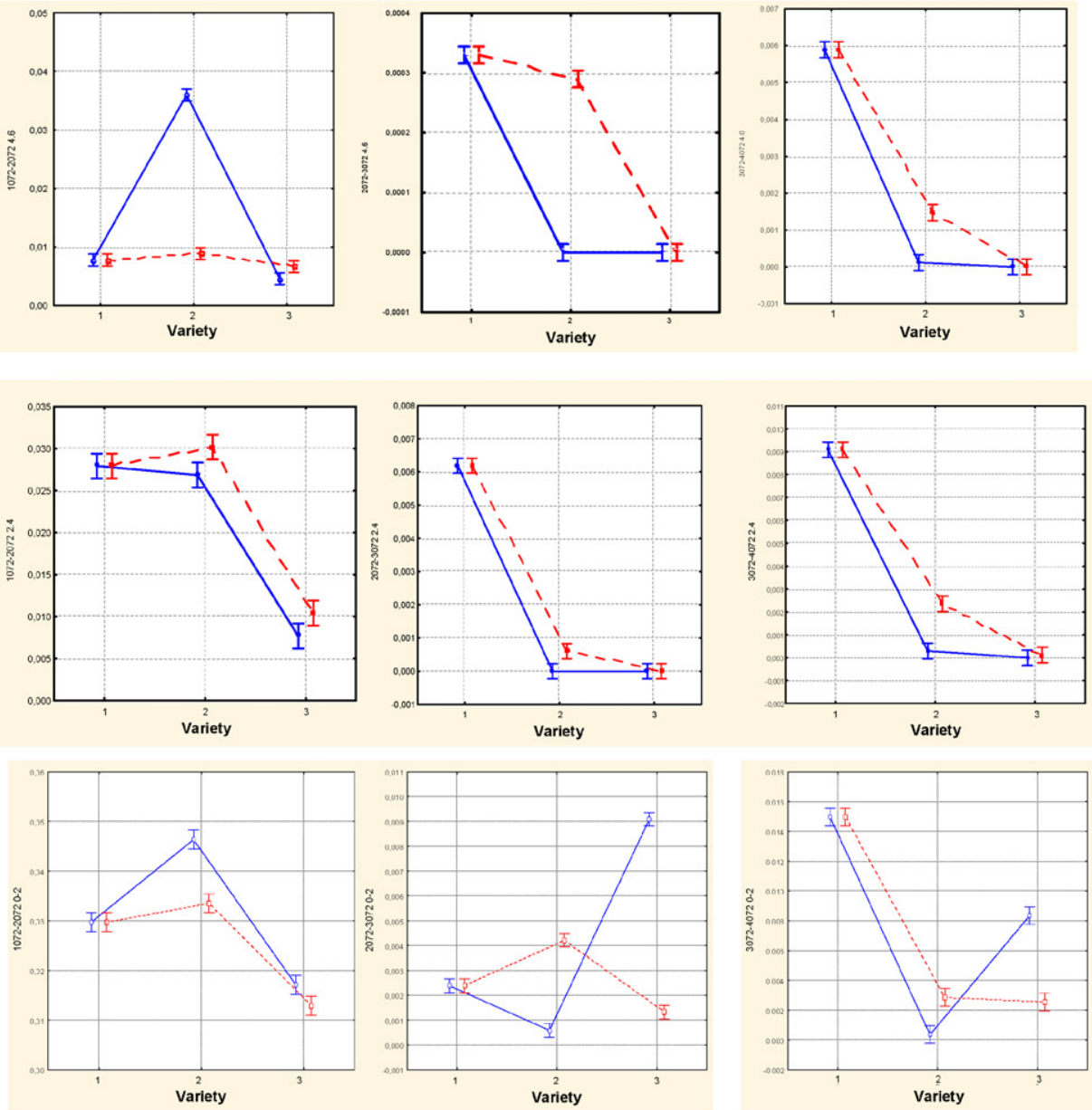

2

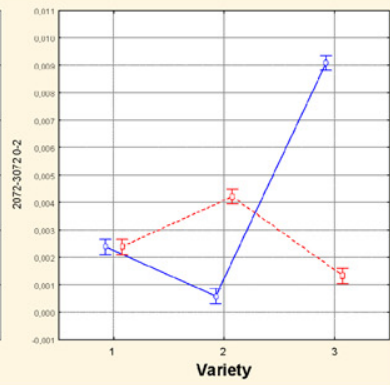

3

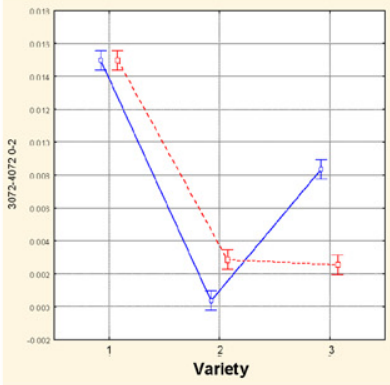

4

---Press

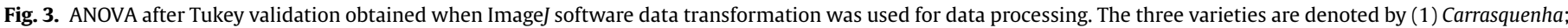

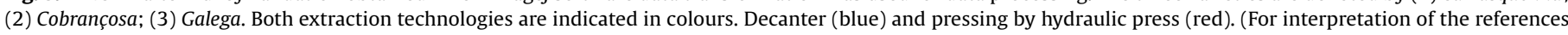
to colour in this figure legend, the reader is referred to the web version of the article.).

performed for complex matrices. The ANOVA after Tukey validation for the results thus obtained for the image transformation results show, that fewer sectors, namely 1c, 2c, 3a, 3c and 4a, are responsible for the significant differences between olive oil samples. In both cases, the ordinate axes presents, in the case of Image $J$ data treatment, the total amount of the area detected for each sector, and in the case of the contour plots areas, the total sector area assigned after processing the data with LECO Corp ChromaTOF $^{\mathrm{TM}}$ software. It is also possible to verify that when Figs. 2 and 3 are compared, the results obtained in sectors $2 b, 2 c$ and $4 c$, by both processing methods, are not significantly different from each other, while for all other quadrants significant differences are verified.

These results means that, after ImageJ transformation into an 8 bit image, there appears to be a loss of significant differences between samples, but the possibility of sample differentiation after multivariate analysis cannot be precluded. PCA was further applied in order to determine which sector/sectors account for the highest discrimination between samples, thus allowing a variable reduction in peaks to be considered. This fact could contribute to reduce the amount of identification work needed for further matrix characterization.

\subsection{Principal components analysis (PCA)}

PCA analysis was performed using the peak areas obtained directly from the contour plots as well as the values obtained using the Image $J$ software, in all the 12 sectors established.

Fig. 4(A) and (B) shows the plot of the objects in the factor plane for the data obtained after LECO Corp ChromaTOF ${ }^{\mathrm{TM}}$ processing and the respective variable loadings. Fig. 5(A) and (B) shows the plot of the objects in the factor plane considering the total area calculated with the Image $J$ treatment system and the respective variable loadings. The total variance explained for the first five principal components when the data were obtained after LECO Corp ChromaTOF ${ }^{\mathrm{TM}}$ processing software and after ImageJ processing software is presented in Tables S3 and S4. The variable loadings for the first two principal components for each data treatment are also indicated in Tables S5 and S6. When the total peak area of each quadrant obtained by the sum of the areas of all the compounds detected in each sector was considered, the first three principal components, with eigenvalues higher then 1.0 , explained $86.18 \%$ of the total variance of the sample. The first two principal components already account for $75.72 \%$ of the total variance (Table S3). On the other hand, when the mapping values were obtained using the 
(A)

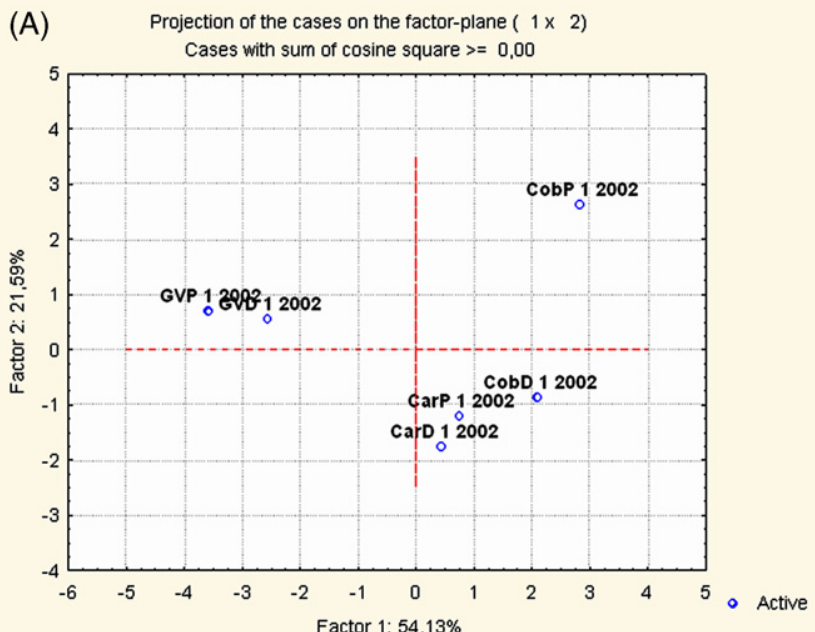

(B)

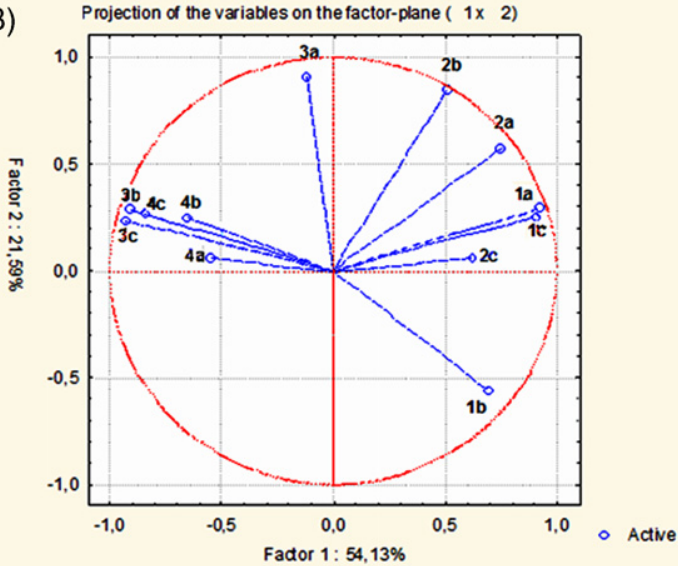

Fig.4. The projection of the objects in the factor plane for the case in which data were obtained (A) after LECO Corp ChromaTOF ${ }^{\mathrm{TM}}$ processing and the respective variable loadings (B).

Image J software, the first three principal components, with eigenvalues higher then 1.0 , explained $94.18 \%$ of the total variance of the sample, where the first two principal components account for $84.00 \%$ of the total variance (Table S4). The total number of samples studied was 18 , and each point in the plots represents the average value of three replicate measurements. For the ChromaTOF ${ }^{\mathrm{TM}}$ processing system, the first three principal components account for more then $86 \%$ of total variance when the respective variables were considered (variables with eigenvalues $>1$ ). For the ImageJ treatment the first three principal components explained more then $94 \%$ of the total variance. After ChromaTOF ${ }^{\mathrm{TM}}$ sample processing, $75 \%$ of the total variance is explained by the first two principal components as it can be perceived in Fig. 4(A) and (B), and $83,9 \%$ of the total variance is explained by the first two principal components when Image J software is used (Fig. 5(A) and (B)).

When ChromaTOF ${ }^{\mathrm{TM}}$ sample processing is considered, the separation achieved is based on compounds present in quadrants $3 \mathrm{~b}$, $3 \mathrm{c}, 4 \mathrm{a}, 4 \mathrm{~b}$ and $4 \mathrm{c}$, which is responsible mainly for the separation of Galega Vulgar from the other two varieties. The Carrasquenha compounds in quadrant $1 \mathrm{~b}$ seem to differentiate this variety from the other two, while for Cobrançosa, the variables located in quadrants $1 \mathrm{a}, 1 \mathrm{c}, 2 \mathrm{a}$ and $2 \mathrm{c}$ account for the separation observed.

In the case of the ImageJ treatment data, the separation of Galega vulgar from the other two varieties is based on compounds present in quadrant 3a; compounds present on sectors 3c, 3b, 4a and $4 b$ separate Carrasquenha variety; Cobrançosa is characterized by com-
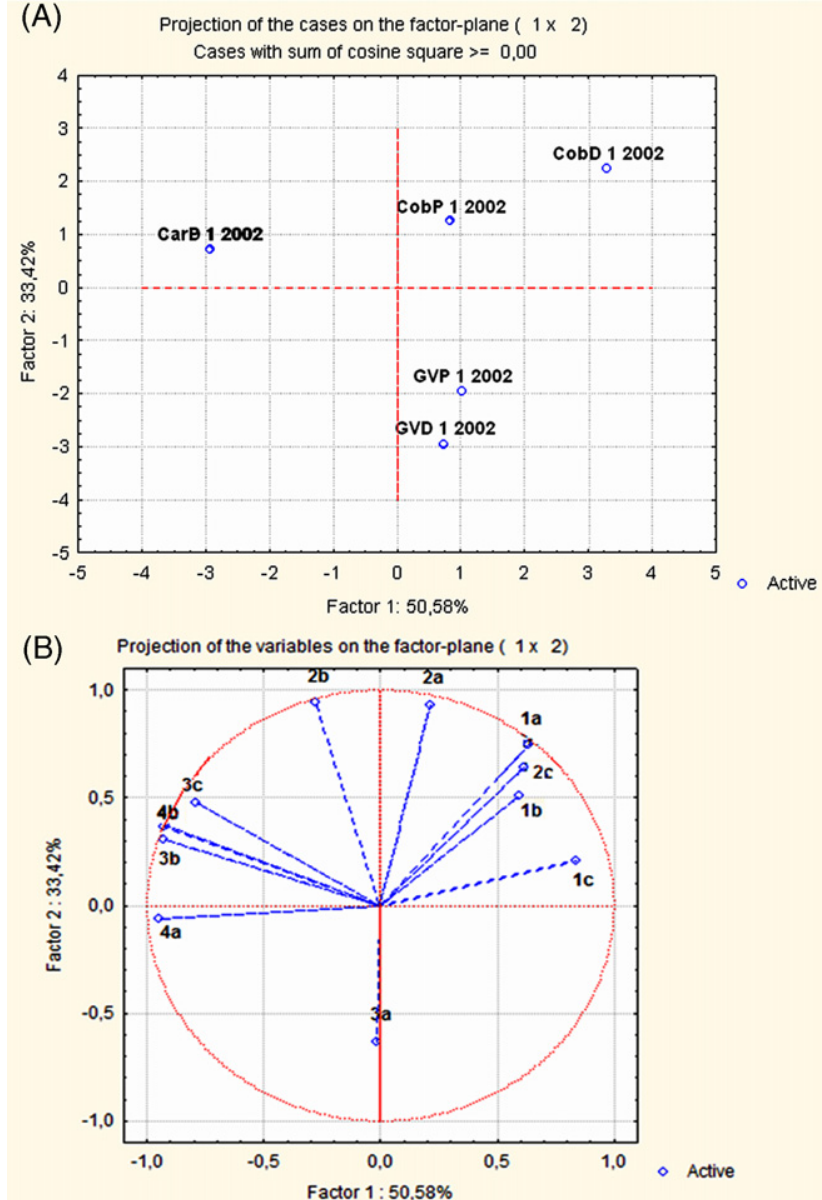

Fig. 5. The projection of the objects in the factor plane considering the total area calculated (A) after ImageJ transformation and the respective variable loadings (B).

pounds in quadrants $1 \mathrm{a}, 1 \mathrm{~b}, 1 \mathrm{c}, 2 \mathrm{a}$ and $2 \mathrm{c}$. Using both approaches, extraction methods can also be distinguished, especially for the Cobrançosa and Galega Vulgar olive oils.

By using this ImageJ software validated by comparison with results that used peak areas as variables one could obtain, not only a better cumulative explained variance after PCA analysis, compared to the ChromaTOF ${ }^{\mathrm{TM}}$ processing system, but also a better separation between varieties which may be seen when Figs. 4(A) and 5(A) are compared. Among samples of the same variety, the PCA performed considering the areas obtained after ChromaTOF $^{\mathrm{TM}}$ processing, allows the differentiation between the two different extraction technologies used for all three olive oil varieties studied, which could not be achieved for the Cobrançosa variety when ImageJ software was used.

Nevertheless, by using this Image J software validated by comparing with results that used peak areas as variables, it is also possible to select compounds that account for most of the separation observed. These compounds are indeed the ones that need to be identified. The complex and time consuming task of identifying all the data obtained by GC $\times$ GC/ToF-MS is simplified considerably. This methodology was never applied before, as far as we know, although it has already been considered to be an evident application for pattern analysis obtained after a GC $\times$ GC experiment [31]. Using this quick and user friendly methodology, one can reduce drastically the amount of data needed for fingerprint characterization. Moreover time needed to extract the important information is also reduced. There is no need for a full identification of all the compounds present in each contour plot to conduct a fingerprint characterization. 


\section{Conclusions}

Comprehensive gas chromatography proved, once again, to be able to extract valuable information that cannot be extracted by one-dimension-GC analysis. This work demonstrated that ImageJ software is a clean and rapid alternative mean to extract correct information from contour plots when fingerprinting is the main objective. The results show that, when the right software is associated with the GC $\times$ GC chromatograms, it is easy to perform a quick and easy fingerprinting analysis, precluding the alignment of the contour plots obtained, which in our study allowed the identification of varieties as well as extraction technologies used to produce high quality olive oils.

These results open the possibility of applying the methodology for authenticity and fraud control purposes, and also for quick matrix characterization, even when operated by non-experts, due the simplicity of the methods involved.

When area results were used a finer separation was obtained in comparison with the 8 bit image.

\section{Acknowledgements}

The authors would like to acknowledge the support of the project POCI/AGR/55432/2004 approved by FCT, and Projecto Agro 824-MADPR and also the valuable contribution of Peter Surovy-from Evora University on using the ImageJ software. The authors would like to express their gratitude to Rui Rocha from Leco Instrumentos S.A. for all his valuable support and Prof. Philip Marriott RMIT Melbourne, Australia for the instrumentation availability. The authors wish also to thank Doutora Ana Maria Phillips for the English revisions.

\section{Appendix A. Supplementary data}

Supplementary data associated with this article can be found, in the online version, at doi:10.1016/j.aca.2008.11.057.

\section{References}

[1] J.M.B. Gouveia, Azeites Virgens do Alto Alentejo. Comportamento Químico, Tecnológico e Sensorial, Universidade Técnica de Lisboa, Instituto Superior de Agronomia (Editor), Lisbon, 1995, p. 520.

[2] E.L. De Lacroix (Ed.), European Commission, Directorate-General for Agriculture, "The olive oil sector in the European Union", European Commission, Directorate-General for Agriculture, 2003, p. 6.

[3] IDRHA (Instituto de Desenvolvimento Rural e Hidráulica, Ministério da Agricultura, do Desenvolvimento Rural e das Pescas), 2007. http://www.idrha.minagricultura.pt/produtos_tradicionais/azeites/index.htm.

[4] V.J.V. Gemas, M.J. Rijo-Johansen, P. Fevereiro, ISHS Acta Horticulturae 586: IV International Symposium on Olive Growing, 2002.

[5] A.F. Vinha, F. Ferreres, B.M. Silva, P. Valentão, A. Gonçalves, J.A. Pereira, M.B. Oliveira, R.M. Seabra, P.B. Andrade, Food Chem. 89 (2005) 561.

[6] M.M. Torres, D.M. Maestri, Food Chem. 96 (2006) 507.

[7] A.G. Vlyssides, M. Loizides, P.K. Karlis, J. Clean. Prod. 12 (2004) 603.

[8] M.T. Morales, R. Aparicio, J. Am. Oil Chem. Soc. 76 (1999) 295.

[9] A. Ranalli, S. Contento, C. Schiavone, N. Simona, Eur. J. Lipid Sci. Technol. 103 (2001) 228 .
[10] A. Ranalli, G. de Mattia, M.L. Ferrante, L. Giansante, La Rivista Italiana delle Sostanze Grasse 74 (1997) 501.

[11] R. Aparicio, G. Luna, Eur. J. Lipid Sci. Technol. 104 (2002) 614.

[12] E. Gimeno, A.I. Castellote, R.M. Lamuela-Raventós, M.C. De la Torre, M.C. LópezSabater, Food Chem. 78 (2002) 207.

[13] C.L. Arthur, J. Pawliszyn, Anal. Chem. 62 (1990) 2145.

[14] J. Ai, Quantitation by SPME before reaching partition equilibrium, in: J. Pawliszyn (Ed.), Applications of Solid Phase Microextraction, Royal Society of Chemistry, Cambridge, UK, 1999, p. 22.

[15] L.H. Ribeiro, A.M. Costa Freitas, M.D.R. Gomes da Silva, Talanta 77 (2008) 110.

[16] L.M.T. Vaz-Freire, A.M. Relva, A.M. Costa Freitas, J. Microcolumn Sep. 13 (2001) 236.

[17] L.M.T. Vaz-Freire, J. Gouveia, A.M. Costa Freitas, Grasas y Aceites 59 (N³)(2008) 260.

[18] S. Vichi, A.I. Castellote, L. Pizzale, L.S. Conte, S. Buxaderas, E. López-Tamames, J Chromatogr. A 983 (2003) 19.

[19] C.A. Zini, F. Augusto, E. Christensen, E.B. Caramão, J. Pawliszyn, J. Agric. Food Chem. 50 (2002) 7199

[20] G. Ouyang, J. Pawliszyn, Trends Anal. Chem. 25 (2006) 692.

[21] A.M. Santos, T. Vasconcelos, E. Mateus, M.H. Farrall, M.D.R. Gomes da Silva, M.R Paiva, M. Branco, J. Chromatogr. A 1105 (2006) 191.

[22] J.M. Davis, J.C. Giddings, Anal. Chem. 55 (1983) 418

[23] A.O. Barakat, A.R. Mostafa, J. Rullkötter, A.R. Hegazi, Marine Pollut. Bull. 38 (1999) 535.

[24] H.-J. de Geus, I. Aidos, J. de Boer, J.B. Luten, U.A.Th. Brinkman, J. Chromatogr. A 910 (2001) 95

[25] M. Adahchour, J. Beens, U.A.Th. Brinkman, J. Chromatogr A. 1186 (2008) 67.

[26] L. Mondello, P.Q. Tranchida, P. Dugo, G. Dugo, Mass Spectrom. Rev. 27 (2008) 101.

[27] K.M. Pierce, J.L. Hope, J.C. Hoggard, R.E. Synovec, Talanta 70 (2006) 797.

[28] K.J. Johnson, R.E. Synovec, Chemom. Intell. Lab. Syst. 60 (2002) 225.

[29] Th. Gröger, M. Schäffer, M. Pütz, B. Ahrens, K. Drew, M. Eschner, R. Zimmermann, J. Chromatogr. A 1200 (2008) 8.

[30] N.E. Watson, W.C. Siegler, J.C. Hoggard, R.E. Synovec, Anal. Chem. 79 (2007) 8270 .

[31] K.M. Pierce, L.F. Wood, B.W. Wright, E. Robert, Synovec, Anal. Chem. 77 (2005) 7735 .

[32] K.M. Pierce, J.C. Hoggard, R.E. Mohler, R.E. Synovec, J. Chromatogr. A 1184 (2008) 341.

[33] P. Surový, N.A. Ribeiro, A.C. Oliveira, L. Scheer, J. For. Sci. 50 (4) (2004) 161.

[34] W. S. Rasband, ImageJ. U.S. National Institutes of Health, Bethesda, MD, USA, 2007 http://rsb.info.nih.gov/ij/index.html.

[35] W. Bailer, Writing ImageJ Plugins-A Tutorial. Version 1.71, 2006. http://rsb.info. nih.gov/ij/download/docs/tutorial171.pdf.

[36] M. Galonska, F. Ducke, T.K-. Zborilova, R. Meyer, H. Guski, F.D. Knollmann, Acad. Radiol. 15 (2008) 222.

[37] A. Kirilova, G. Lockwood, P. Choi, N. Bana, M.A. Haider, K.K. Brock, C. Eccles, L.A Dawson, Int. J. Radiat. Oncol. Biol. Phys. 71 (4) (2008) 1189.

[38] M. Pool, J. Thiemann, A.B-. Or c, A.E. Fournier, J. Neurosci. Methods 168 (2008) 134.

[39] C. Igathinathane, L.O. Pordesimo, E.P. Columbus, W.D. Batchelor, S.R. Methuku, Comput. Electron. Agric. 63 (2008) 168.

[40] P.J. Marriott, R. Shellie, Trends Anal. Chem. 21 (2002) 573.

[41] P.J. Marriott, R.M. Kinghorn, Anal. Chem. 69 (1997) 2582.

[42] G. Eyres, J.-P. Dufour, G. Hallifax, S. Sotheeswaran, P.J. Marriott, J. Sep. Sci. 28 (2005) 1061.

[43] X. Di, R.A. Shellie, P.J. Marriott, C.W. Huie, J. Sep. Sci. 27 (2004) 451.

[44] D. Ryan, P. Watkins, J. Smith, M. Allen, P. Marriott, J. Sep. Sci. 28 (2005) 1075.

[45] Z.L. Cardeal, M.D.R. Gomes da Silva, P.J. Marriott, Rapid Commun. Mass Spectrom. 20 (2006) 2823.

[46] E.P. Mateus, M.D.R. Gomes da Silva, A.B. Ribeiro, P.J. Marriott, J. Chromatogr. A 1178 (2008) 215

[47] Z.L. Cardeal, P.P. de Souza, M.D.R. Gomes da Silva, P.J. Marriott, Talanta 74 (2008) 793.

[48] P.A. Marques, L. Vaz-Freire, A.M. Freitas, Proceedings of the $8^{\circ}$ Encontro de Química dos Alimentos, Beja, Portugal, 2007, p. 183. ISBN: 978-972-99080-9-5. 